\title{
Electrochemistry of Cyclodextrin Inclusion Complexes of Pharmaceutical Compounds
}

\author{
Abd-Elgawad Radi* and Shimaa Eissa
}

Department of Chemistry, Faculty of Science (Dumyat), Mansoura University; 34517 Dumyat, Egypt

\begin{abstract}
Electrochemistry of cyclodextrins (CDs) and cyclodextrin inclusion complexes with different pharmaceutical compounds is reviewed. The article highlights some electrochemical investigations of the CD-drugs interactions in solution. Cyclodextrin modified electrodes and their applications as electrochemical sensors in pharmaceutical analysis based on the self-assembly of CD derivatives on metal electrodes and nanoparticles, and cyclodextrin-modified multiwalled carbon nanotubes are also discussed.
\end{abstract}

Keywords: Cyclodextrins, pharmaceutical, electrochemical sensors, modified electrodes.

\section{INTRODUCTION}

Cyclodextrins (CDs) are a well-known class of natural host molecules obtained from the enzymatic degradation of starch [1-5]. They consist of n $\mathrm{D}(+)$ glucopyranose units linked together by $\alpha-(1,4)$ bonds. Depending on the number of sugar units that constitute the structure, the three unmodified CDs are $\alpha, \beta$ and $\gamma$-CD which correspond to $\mathrm{n}=$ 6,7 and 8 , respectively (Fig. 1). The overall shape of CDs looks like a truncated cone with the narrow side formed by the primary 6-hydroxyl groups and the wider side by ring of hydrogen bonds formed between the 2-hydroxyl and the 3-hydroxyl groups of adjacent glucose units gives the $C D$ a remarkably rigid structure. The three natural cyclodextrins $\alpha-, \beta-$, and $\gamma$-CDs differ in their ring size and solubility (Table 1) [6].

\section{CYCLODEXTRINS INCLUSION COMPLEXES}

One of the most important characteristics of CDs is the formation of inclusion complexes with various organic and inorganic guest molecules [6-9]. Upon inclusion

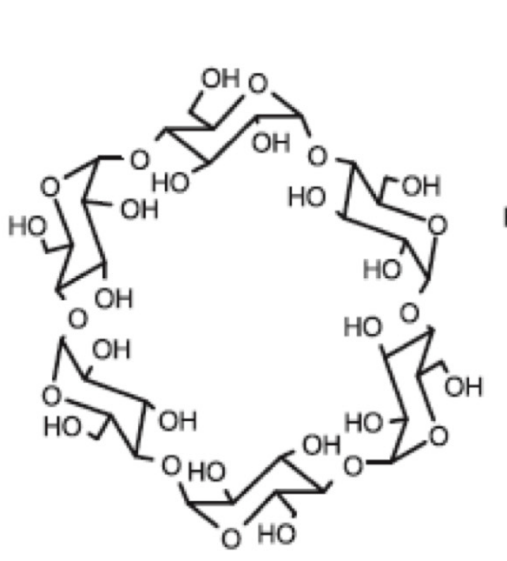

$\alpha-C D$

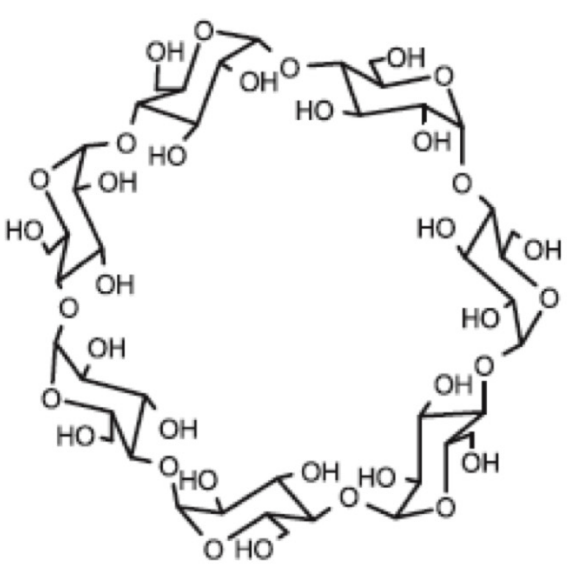

B-CD

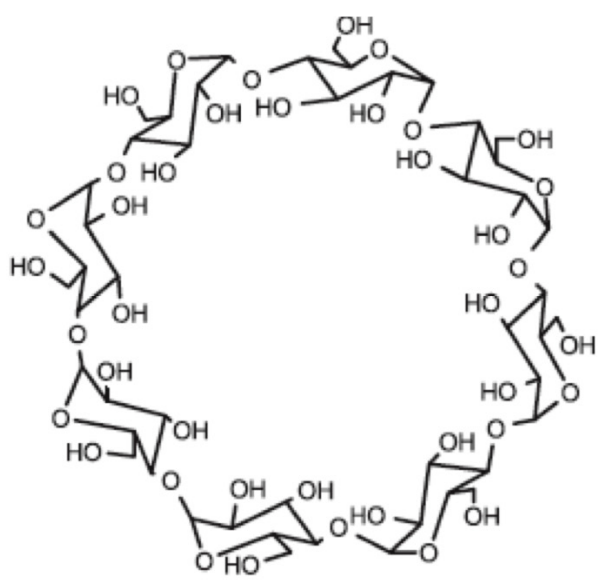

$\gamma-C D$

Fig. (1). Chemical structures of $\alpha-, \beta-$, and $\gamma$-CD.

secondary 2-and 3- hydroxyl groups. The cavity is lined by the hydrogen atoms and the glycosidic oxygen bridges. Therefore, CDs have a relatively hydrophobic cavity compared to water, while the outer surface is hydrophilic. A

*Address correspondence to this author at the Department of Chemistry, Faculty of Science (Dumyat), Mansoura University; 34517 Dumyat, Egypt; Tel: +20-57-2403866; Fax:+20-57-2403868; E-mail: abdradi@yahoo.com complexation, the characteristic properties of the guest molecule inside the CD cavities, such as solubility, chemical reactivity, electrochemical properties and spectral properties will be changed significantly. This unique property has led to widespread utilization of CDs in pharmaceutical, food, chemical and other industrial areas. The stability of the inclusion complexes depends on the size and the polarity of the guest molecules, the nature of the medium, and the 
temperature. Based on size selective complexation properties of CDs, the better the fit of guest molecules inside the cavity of $\mathrm{CD}$, the more stable the complex will be. The stability of the complex is inversely proportional to the polarity of the guest molecule. Several hypotheses have been proposed for the driving forces for the $\mathrm{CD}$ inclusion complexation, including van der waals interactions and hydrophobic interactions between the hydrophobic moiety of the guest molecules and the CD cavity, hydrogen bonding between the polar functional groups of the guest molecules and the hydroxyl groups of CDs, release of high-energy water in the cavity in the complex formation, and release of strain energy in the ring frame system of the CD. Among those forces, hydrophobic interactions are frequently considered as the main driving force for the complexation in aqueous media between hosts containing apolar cavities and non polar guest molecules.

Table 1. Some Properties and Dimensions of Four Most Common CDs

\begin{tabular}{|c|c|c|c|}
\hline $\begin{array}{c}\text { Type of } \\
\text { CD }\end{array}$ & $\begin{array}{c}\text { Cavity } \\
\text { Diameter } \AA\end{array}$ & $\begin{array}{c}\text { Molecular } \\
\text { Weight }\end{array}$ & $\begin{array}{c}\text { Solubility } \\
(\mathbf{g} / \mathbf{1 0 0} \mathbf{~ m L})\end{array}$ \\
\hline \hline$\alpha-\mathrm{CD}$ & $4.7-5.3$ & 972 & 14.5 \\
\hline$\beta-\mathrm{CD}$ & $6.0-6.5$ & 1135 & 1.85 \\
\hline$\gamma-\mathrm{CD}$ & $7.5-8.3$ & 1297 & 23.2 \\
\hline$\delta-\mathrm{CD}$ & $10.3-11.2$ & 1459 & 8.19 \\
\hline
\end{tabular}

\section{PHARMACEUTICAL APPLICATIONS OF CYCLO- DEXTRINS}

CDs and their derivatives have received considerable attention in the pharmaceutical field for the past few years and an increased number of reviews have been dedicated to their pharmaceutical applications [10-20]. CDs and their derivatives have well-known effects on drug solubility and dissolution, bioavailability, safety and stability, and their applications in different areas of drug delivery have been also reported. However, the cavity size of $\alpha-C D$ is insufficient for many drugs and $\gamma-\mathrm{CD}$ is expensive. Among $\mathrm{CDs}, \beta-\mathrm{CD}$ is receiving increasing attention due to its low cost and cavity size suitable for the widest range of drugs in aqueous media. But the low aqueous solubility and nephrotoxicity limited the use of $\beta-C D$ especially in parenteral drug delivery [21]. Chemical modifications of parenteral CDs have been developed to extend the physicochemical properties and inclusion capacity of parent cyclodextrins $[22,23]$.

\section{ELECTROCHEMICAL STUDIES OF CYCLO- DEXTRINS AND CYCLODEXTRIN INCLUSION COMPLEXES}

Cyclodextrins (CDs) with their largely hydrophobic cavities of variable size and numerous ways of chemical modification are the subject of intensive electrochemical research including both their behavior in homogeneous solutions and in thin films attached to the electrode surfaces [24-26]. Electroanalytical methods measuring the current response to the potential applied, linear scan, staircase, and pulse voltammetries, and potential-step techniques such as chronoamperometry and chronocoulometry, allow to trigger or to monitor changes in the redox states of the electroactive sites in CD-based systems. Linear scan (LSV) or staircase (SCV) cyclic voltammetries are the most frequently employed electrochemical techniques for studies of electroactive CD systems. They provide useful information on the nature the reduced and oxidized forms of the studied compounds, and on the mechanistic aspects of the electrode processes. They also allow monitoring even very subtle changes of the molecular environment of the redox centers by following their redox potentials. If the concentrations of the redox compounds in the solution or at the electrode surface are low, and better sensitivities are needed than those optimal for LSV and SCV, differential pulse (DPV), normal pulse (NPV) and Osteryoung square-wave voltammetries (OSWV) are more suitable [27]. They allow better elimination of the capacitive/background currents and, therefore, the measurement of smaller faradic signals becomes easier. CDs are employed in electrochemical sensing devices for the determination of selected analytes. The characterization of cyclodextrin (CD) systems by electrochemical methods, mainly by cyclic voltammetry has been discussed by Matsue et al. [28]. The addition of CD to the electrolyte solution causes a decrease in the peak current and also a shift in the apparent half-wave potential in cyclic voltammetry. Quantitative analysis in the both phenomena affords the formation constants of $\mathrm{CD}$ complexes. The formation or dissociation rate constants can be evaluated from the cyclic voltammetric data at high scan rates.

\section{CALCULATION OF THE STABILITY CONSTANTS FOR HOST-GUEST COMPLEXES USING ELECTRO- CHEMICAL METHODS}

Among the various approaches for the determination of stability constants, electrochemical methods are very useful, especially when the guest molecule is electroactive. In the case of a reversible electroreduction process, in which a complex is formed between an electroactive guest $\mathrm{G}$ and a host ligand $\mathrm{H}$ according to a general equation:

$\mathrm{G}+p \mathrm{H} \rightleftharpoons \mathrm{GH}_{p}$

The stability constant $\mathrm{K}$ and stoichiometric coefficient $p$ can be determined from:

$E_{1 / 2}^{G(H)}=E_{1 / 2}^{G}-\frac{R T}{n F} \ln K-\frac{R T}{n F} \ln a_{H}^{p}$

where $E_{1 / 2}^{G(H)}$ and $E_{1 / 2}^{G}$ are the half-wave potentials for the complex and the guest, respectively, $a_{H}^{P}$ is the activity of the host ligand, $\mathrm{R}$ is the gas constant, $\mathrm{J} \mathrm{mol}^{-1} \mathrm{~K}^{-1}, \mathrm{~T}$ is temperature, $\mathrm{K}, \mathrm{n}$ is the number of electrons transferred in the electrode reaction and $\mathrm{F}$ is the Faraday constant 96484.6 $\mathrm{C} \mathrm{mol}^{-1}$. From the plot of $E_{1 / 2}^{G(H)}$ vs logarithm of the concentration of the host $\mathrm{H}$ (assuming no strong deviation from its activity) the value of $p$ can be obtained from the slope and $\mathrm{K}$ from the intercept. This equation assumes that only the oxidized form of the guest is complexed and the ligand concentration greatly exceeds that of the guest. When the guest upon reduction to a lower oxidation state still forms a complex with the host, the $\mathrm{E}_{1 / 2}$ dependence on ligand concentration gives only the difference in $p$ values and the 
ratio of $\mathrm{K}$ values of the two complexes of the guest in the two oxidation states. When an electroinactive guest is added to a solution of an electroactive host, a titration curve is obtained of $E_{1 / 2} v s$ concentration of $\mathrm{G}$ [29]:

$$
E_{1 / 2}[G(H)]=E_{1 / 2}[G]+\frac{R T}{2 n F} \ln \frac{\left(1+K_{m+}[G]\right)}{\left(1+K_{n+}[G]\right)}
$$

where $\mathrm{K}_{\mathrm{m}+\mathrm{t}}$ and $\mathrm{K}_{\mathrm{n}+\mathrm{f}}$ are the binding constants of the guest $\mathrm{G}$ with the host $\mathrm{H}$ in its $\mathrm{m}^{\prime+}$ and $\mathrm{n}^{+}$"oxidation states. Recording the half-wave or mid-point potential value before and after the addition of large excess of guest to an electroactive host solution has often been used to evaluate the ratio of binding constants in the oxidized and reduced form of the host [30].

Of special interest is the evaluation of the binding affinity of a guest to a ligand immobilized on the electrode surface. Cyclic voltammograms recorded for increasing concentration of guest in the solution using a CD-modified electrode as host allows us to calculate the binding constant to the surface-immobilized cyclodextrin. The association constant of the guest with surface-confined $\mathrm{CD}, \mathrm{K}_{1}$ is usually determined by fitting the experimental data to the following equation:

$$
\frac{[G]}{I_{P a}}=\frac{1}{K_{1} I_{\max }}+\frac{[G]}{I_{\max }}
$$

where $I_{p a}$ is the anodic peak current for a given concentration of guest [G] in the linear part of the $\mathrm{I}_{\mathrm{pa}} v s[\mathrm{G}]$ plot, $\mathrm{I}_{\max }$ is the maximum peak current when the current attains constancy. $K_{1}$ is calculated from the $x$-intercept of the linear part of the plots for different scan rates [31,32].

\section{ELECTROCHEMICAL INVESTIGATIONS OF THE CD-DRUGS INTERACTIONS IN SOLUTION}

The formation of inclusion complexes is the point of interest in most electrochemical investigations of CDs in solution. Binding constants in solution are usually determined from potentiometric titrations or plots of cyclic voltammetry peak potentials $v s \mathrm{CD}$ concentration after assessing the guest/host ratio in the complex $[33,34]$. Potentiometric measurements are more frequently used in studying the inclusion complexes of pharmaceutical compounds with cyclodextrins [35-48], and ion-selective electrodes are employed, for the direct measurement of the guest activity in the solution [49-52]. Decreased peak currents in cyclic voltammetry and shifts in the oxidation and reduction potentials are observed on complexation, owing to the smaller diffusion coefficients of the complexes than that of the guest alone, and to the relatively high stability of these complexes.

The effects of $\beta$-cyclodextrin ( $\beta$-CD) on the electrochemical behaviour of barbitone sodium have been studied using electrochemical techniques [53]. The redox activity of barbitone sodium in both the absence and presence of, $\beta-C D$ was assessed by an electrochemical method in $0.05 \mathrm{M}$ potassium nitrate-nitric acid $(\mathrm{pH} 1.8)$ solution. While the complexation reaction remains in equilibrium, the apparent formation constant of the inclusion complex was calculated to be $326 \mathrm{M}^{-1}$ under equilibrium conditions at $20^{\circ} \mathrm{C}$. A stable menadione- $\beta$-cyclodextrin inclusion complex was prepared and characterised by cyclic voltammetry [54].

Electrochemical properties of phenylhydrazine hydrochloride $(\mathrm{PH})$ in aqueous solutions in the presence of $\beta$-cyclodextrin ( $\beta$-CD) [55] and $\alpha$-cyclodextrin $(\alpha-C D)[56]$ have been investigated. It was found that its electrochemical oxidability in aqueous solutions could be greatly suppressed in the presence of $\alpha-\mathrm{CD}$ and $\beta-\mathrm{CD}$. For strongly adsorption of $\mathrm{PH}$ on glassy carbon electrode, the formation constant cannot be determined by voltammetric methods.

The inclusion of some pharmaceutically related molecules, such as 1,4-benzoquinone (BQ), 9,10anthraquinone (AQ), anthracene (AN), acridine (AC), phenothiazine (PT) and thianthrene (TH) within $\beta$ cyclodextrin ( $\beta-C D)$ has been investigated using an electrochemical method [57]. From the decrease in the peak current, the formation constants $\left(\mathrm{K}_{\mathrm{f}}\right)$ of these inclusion complexes were obtained. The experimental results suggest that both the dimension and polarity of the guest molecule affects the inclusion complex stability. $\beta-\mathrm{CD}$ is able to accommodate both $\mathrm{BQ}$ and $\mathrm{AQ}$, but due to the steric factor, the two kinds of molecules penetrate into the cavity by different models. AN, PT, TH and AC, whose dimensions are similar, are included by $\beta-C D$ with $\mathrm{K}_{\mathrm{f}}$ decreasing in the order $\mathrm{TH}>\mathrm{AN}>\mathrm{PT} \gg \mathrm{AC}$. These phenomena can be explained in terms of polarity, i.e. electron-accepting ability of the hybrid atoms in 9,10-positions.

A new $\beta$-cyclodextrin ( $\beta$-CD) derivative, mono[6 -deoxy6-(2-butenedinitrile-2,3-dimercapto sodium salt)]- $\beta$ - $C D$ (6- $\beta$ $\mathrm{CD}$ ), and its inclusion compound with a ferrocenium, have been prepared and characterized by cyclic voltammetry (CV) [58]. The interaction between the guest and the host with side-arm in 6-mnt- $\beta-\mathrm{CD}^{-} / \mathrm{Fc}^{+}$resulted in smaller positive potential shifts compared to that in the inclusion compound $\left[\beta-\mathrm{CD} / \mathrm{Fc}^{+}\right] \mathrm{BF} 4^{-}$.

The interaction of the anti-inflammatory drug indomethacin (IMC) with $\alpha$-, $\beta$-cyclodextrins (CDs) have been investigated in the Britton-Robinson (BR) buffer $(\mathrm{pH}=$ 7.2) using voltammetric methods [59]. The measurements show that the IMC molecule is inserted, from the $p$ chlorobenzoyl part, into the cavity of the cyclodextrins. The interaction of IMC with CDs causes pronounced changes in the electrochemical behaviour of the drug. The stoichiometry of complexes formed in solution is inferred to be $1: 1$. The binding constants were calculated from the decrease in peak current of IMC upon the addition of the host molecules. IMC has a higher affinity for $\beta-C D$ than for $\alpha-C D$, as the IMC- $\beta$ $\mathrm{CD}$ interaction is the most exergonic.

The inclusion of the antibacterial drug nalidixic acid (NAL) in $\alpha$ - and $\beta$-cyclodextrin (CD) cavities has been studied using voltammetric methods [60]. A pronounced decrease in the peak currents of NAL was noticed upon the addition of $\alpha$ - and $\beta$-CDs. From the changes in the peak currents, it was concluded that NAL forms 1:1 inclusion complexes with the various hosts, which was also revealed in the phase solubility profile of the NAL- $\beta$-CD system, as a representative example. From voltammetric data, the logarithms of the binding constants were calculated to be 2.60 and 3.20 for $\alpha$ - and $\beta$-CDs, respectively. The magnitude of the formation constants, as well as the Gibbs free energies 
for NAL with $\alpha$ - and $\beta$-CDs, showed that NAL was bound more strongly to $\beta-\mathrm{CD}$, with a more apolar cavity, than to $\alpha$ CD. These observations suggested that hydrophobic interaction was the most important recognition element in the binding process. It was inferred that the inclusion process can occur through the 2-methylpyridine side. An additional hydrogen bond was also found to be formed between the carboxyl group of NAL, which remains outside the $\beta-C D$ cavity, and the secondary hydroxyl group of $\beta-\mathrm{CD}$. This hydrogen bond should, therefore, be operating as an important second recognition element in the NAL- $\beta-C D$ system.

The host-guest inclusion behavior of anticancer drug irisquinone with $\beta$-cyclodextrin has been studied [61]. The variance of the reduction wave of irisquinone in the absence and presence of $\beta$-cyclodextrin was examined by cyclic voltammetry at the hanging mercury drop electrode. In $\mathrm{pH}$ 6.8 supporting electrolyte which was close to physiological condition, the introduction of $\beta$-cyclodextrin resulted in both decrease of reduction current and the positive shift of peak potential of reduction wave of irisquinone. The electroactive guest molecule irisquinone was complexed with host molecule $\beta$-cyclodextrin to the formation of $1: 1$ inclusion complex. The stability constant $\mathrm{K}_{\mathrm{f}}$ was $1.92 \times 10^{3} \mathrm{M}^{-1}$ by the electric current method.

The inclusion complexes of catecholamines (dopamine, $\mathrm{DA}$, and adrenaline, $\mathrm{AD})$ with $\beta$-cyclodextrin $(\beta-\mathrm{CD})$ have been studied by cyclic voltammetry (CV) using glassy carbon electrode (GCE) for expanding the potential window [62]. The variations of peak potential and peak current were observed on cyclic voltammograms, when the electroactive guest molecules, $\mathrm{DA}$ and $\mathrm{AD}$ were complexed with $\beta-\mathrm{CD}$. Dissociation constants of cyclodextrin inclusion complexes have been calculated. The experimental results indicated that both $\mathrm{DA}$ and $\mathrm{AD}$ can form 1:1 inclusion complexes with $\beta$ $\mathrm{CD}$ in aqueous solutions. Furthermore, it was found that their electrochemical oxidation in the aqueous solutions could be inhibited by $\beta-C D$.

The interaction of lumazine, an antibacterial drug, with $\alpha-, \beta$-cyclodextrins in aqueous solution has been studied by differential pulse stripping voltammetry and cyclic voltammetry at the hanging mercury drop electrode [63]. The electrochemical and absorption spectral data indicated a 1:1 complex formation of lumazine with $\alpha$-, $\beta$-cyclodextrins. It was found that the complexation of lumazine molecules enhances the stacking interactions which might facilitate the formation of a perpendicularly stacked layer of lumazine- $\alpha-$ cyclodextrin complex on the electrode surface. Based on the variations in the current or absorbance, the formation constants and consequently, the Gibbs energy of these complexes were determined. The small size cavity of $\alpha-$ cyclodextrin was found to have a greater affinity for lumazine than the $\beta$-cyclodextrin.

The $\beta$-cyclodextrins-hexamethylenetetramine inclusion complex produced a reduction peak on the $2.5^{\text {th }}$ order differential liner sweep voltammetry curve [64]. The peak current was linear with the concentration of hexamethylenetetramine and a method has been applied to determine hexamethylenetetramine with satisfactory results as compared with conventional method. The mechanism of the molecular recognition and the characters of inclusion complex have been also studied.

The interactions between rutin or the inclusion complex of rutin- $\beta$-cyclodextrin and DNA were investigated by cyclic voltammetry [65]. The results showed that the benzopyranic4-one plane of rutin mainly intercalated into DNA in the absence of $\beta$-cyclodextrin, while the catecholic portion of rutin was located in the double helix of DNA in the presence of $\beta$-cyclodextrin.

Cyclic voltammetry has been used to monitor the inclusion phenomena of $\beta$-lapachone [66], a natural orthonaphthoquinone that has been shown to have a variety of pharmacological effects, mainly anticancer activity, within the cavity of $\beta$-cyclodextrin, together with studies concerning the competitive effects of ethanol concentration on this behavior. A value of $15 \pm 5 \mathrm{M}^{-1}$ was found for the association constant between $\beta$-lapachone and $\beta$-cyclodextrin in phosphate buffer, in the presence of $5 \%$ ethanol. The electrochemical behavior of the $\beta$-lapachone reduced form suggested external interactions between the hydroquinone and $\beta$-cyclodextrin via the formation of hydrogen bonds. Electrochemical studies were also performed in the presence of oxygen, since the redox environment of $\beta$-lapachone biological targets was considered very important for its therapeutical efficiency. In the presence of $\mathrm{O}_{2}, \beta$-lapachone has shown a catalytic reduction wave, related probably to an electron transfer to oxygen, generating oxygen reactive species and giving back the parent quinone, leading thus to a redox cycle, with a kinetic apparent constant of $40 \mathrm{~s}^{-1}$. These in vitro results correlated with in vivo activities.

The host-guest interaction between cyclodextrins and steroids has been studied by electrochemical techniques [67]. The interaction of estrone and estradiol with $\beta$-cyclodextrins $(\beta-C D)$ has been investigated by differential pulse voltammetry (DPV) and high-performance liquid chromatography (HPLC) in mixed media [68]. The cosolvent influence on the tendency of these estrogens to form inclusion complexes with $\beta$-CD was examined. Thus, acetonitrile $(\mathrm{MeCN})$ and ethanol $(\mathrm{EtOH})$ were used in a mixed aqueous medium containing phosphate buffer. The association constant $\left(\mathrm{K}_{\mathrm{a}}\right)$ of the inclusion complexes of estrone and estradiol with $\beta-\mathrm{CD}$ were determined in two different media by using both voltammetric and chromatographic techniques. Estradiol was found to bind to $\beta$-CD with higher affinities than estrone, irrespective of the medium. A clear influence of the co-solvent on the $\mathrm{K}_{\mathrm{a}}$ value was found, suggesting a competition of co-solvent molecules with estrogens for binding to the cavity of $\beta-\mathrm{CD}$. Consequently, interaction between $\beta-\mathrm{CD}$ and the steroids was weakened when acetonitrile was used. The formation of inclusion complexes between estradiol and sulfobutyleter- $\beta$ $\mathrm{CD}$ (SBCD) and hydroxypropil- $\beta-\mathrm{CD}$ (HPCD) has been also studied by chronocoulometric and differential pulse voltammetry [69]. In presence of CD there was a decrease of the cathodic peak current with the increase of the amount of $\mathrm{CD}$. This decrease was due to the lower diffusion coefficient (D) of estradiol-cyclodextrin complex compared with the free guest. The addition of CDs produced a maximum decrease of $20 \%, 22 \%$ and $30 \%$ in the diffusion coefficient with $\mathrm{CD}, \mathrm{SBCD}$ and $\mathrm{HPCD}$, respectively. Using the variation in $\mathrm{D}$, association constants of $132 \pm 18,247 \pm 32$ 
and $276 \pm 28 \mathrm{M}^{-1}$ for $\mathrm{CD}, \mathrm{HPCD}$ and SBCD were determined.

A systematic comparative study of the binding of antitumor morin, morin- $\beta-\mathrm{CD}$, and morin- $\mathrm{Cu}$ complexes with DNA has been investigated in the Britton-Robison (BR) buffer solutions using voltammetric and spectroscopic methods [70]. The results showed that morin molecule, acting as an intercalator, was inserted into the cavity of the $\beta$-cyclodextrin $(\beta-C D)$ as well as into the base stacking domain of the DNA double helix. The interaction of morin$\mathrm{Cu}$ complex or the inclusion complex of morin- $\beta-\mathrm{CD}$ with ds-DNA caused pronounced changes in the electrochemical behavior of the morin complexes. The intercalation of morin- $\mathrm{Cu}$ and morin- $\beta-\mathrm{CD}$ complexes with DNA produced an electrochemically inactive supramolecular complex. The binding constants were calculated from the decrease in peak current of morin and its complexes upon the addition of the host molecules.

\section{PREPARATION OF CYCLODEXTRIN MODIFIED ELECTRODES}

Several techniques were used for the preparation of cyclodextrin modified electrodes. Some of the common methods are mentioned below:

\subsection{Langmuir-Blodgett (L-B) Technique}

Langmuir monolayers at the air-water interface and L-B monolayers obtained on transfer of these films onto solid substrates require that the molecules are amphiphilic and organize into ordered layers, so several modifications of the CDs have been proposed [71]. Various amphiphilic $\alpha$ - and $\beta$ CDs functionalized with alkyl chains at the primary hydroxy positions or modified on the secondary face form stable and well-organized monomolecular layers at the air-water interface $[72,73]$. They can then be used for the preparation of L-B films on solid substrates. Electroactive CDs persubstituted with electroactive groups, e.g. terathiafulvalene (TTF) moieties [74], were transferred as L$B$ films from the water surface with a transfer ratio of 1 to the solid substrate. Charge-transfer interactions in the L-B films were then studied and new sensing devices were proposed [75-79].

\subsection{Self-Assembly Method}

Self-assembled monolayers (SAMs) provide a simple way to functionalize coinage metal electrode surfaces by organic molecules containing anchor groups such as thiols, disulfides, or silanes. The monolayers are usually well packed, ordered, and stable and can be easily tailored for certain applications by changing the functional terminal group in contact with the solution. Alkanethiol monolayers can provide a membrane matrix useful for immobilizing structures such as cylodextrins [80-82].

The formation and successful in situ imaging of "nanotube" structures of $\beta-\mathrm{CD}$ at controlled electrode potentials has been described by Ohira et al. [83]. The selforganization of $\beta-\mathrm{CD}$ into a "nanotube" structure similar to that of CD-polyrotaxane was found to be induced by potential-controlled adsorption on $\mathrm{Au}$ (III) surfaces in sodium perchlorate solution. In situ STM revealed that the cavities of $\beta-\mathrm{CD}$ faced sideways not upward in the tubes. This ordered structure can form only under conditions where the appropriate potential is applied to the surface. $\beta-C D$ molecules were in a disordered state on bare $\mathrm{Au}$ (III) surfaces without potential control.

\subsection{Cyclodextrin-Multiwalled Carbon Nanotubes Modified Electrodes}

Owing to their chemical stability and electrical conductivity, carbon nanotubes (CNTs) are frequently employed as an immobilizing matrix for chemical and biological active species, including $\beta-\mathrm{CD}$. Generally, CNTmodified electrodes show improved sensing performance with enhanced sensitivity for detecting various analytes. Electrodes modified with multi-walled carbon nanotubes (MWNTs) in which $\beta$-CD have been incorporated have recently been successfully used to study and quantify some pharmaceutical compounds, because of the promising properties of both materials [84-89].

\subsection{Preparation of Polymer Films}

Thin polymer films of CDs can be prepared on an electrode surface by polycondensation with dialdehyde or by electropolymerization following derivatization. CD polymers (CDP) as modifiers of metal and carbon electrodes have been investigated by Kutner et al. [90-96]. In some cases the stability of complexes embedded in the polymer matrix was found to be enhanced [91, 97-99].

\subsection{Carbon Paste Electrodes Modified With Cyclodextrins}

Cyclodextrins can be used as a component in preparation of carbon-paste electrodes. Since modified carbon paste electrodes have acquired greater importance in the field of electrochemistry due to their low residual current and less noise and because they are very cheap and easy to prepare and replace [100-102]. These electrodes have a wide range of anodic and cathodic applications.

\section{APPLICATIONS OF CYCLODEXTRIN MODIFIED ELECTRODE IN PHARMACEUTICAL ANALYSIS}

Voltammetric responsive sensors based on organized self-assembled $\beta$-cyclodextrin derivative monolayers on a gold electrode ( $\beta$-CD-SME) for electroinactive ursodeoxycholic and dehydrocholic acids have been studied [103]. Both theoretical considerations and experimental results proved that the reduction in the oxidation peak current of the electroactive marker, ferrocene caboxylic acid, at $\beta$-CD-SME was proportional to the concentration of the target molecule and the formation constant of the inclusion complexes with $\beta$-CD could be evaluated. The application of the sensor as a detector for ursodeoxycholic and dehydrocholic acids after capillary electrophoresis (CE) separation has been tested. This sensor provided an alternative approach for the detection of electroinactive organic species, and was expected to find application in liquid chromatography (LC) and CE detection.

A molecular imprinting method involving a three step sequential self-assembly procedure has been applied to prepare gold electrodes responsive towards ibuprofen [82]. The electrode modified with the cyclodextrin derivative binds ferrocene to form an electroactive complex with the ferrocene oxidation current decreasing in the presence of ibuprofen in the solution. The competition of ferrocene and 
ibuprofen for the cyclodextrin cavities in the monolayer provided a means for the determination of the binding constants of ibuprofen with two derivatives of lipoylamide $\beta$ cyclodextrin of different hydrophobicity.

Electrode reactions of catecholamines were investigated by employing a gold electrode covered with a monolayer of a cyclodextrin derivative [104], which was prepared from bis $(\omega$-carboxyundecyl) disulfide and 6-amino-6-O-deoxy- $\beta$ cyclodextrin. The electrode reaction of L-DOPA was mostly prevented by a 1-monolayer at the surface of a gold electrode. On the other hand, the electrode reactions of dopamine, norepinephrine, and epinephrin still maintained about $50-30 \%$ of their original values when compared with corresponding anodic peak currents. Combining the results on the electrode reactions of ferrocene derivatives at the 1monolayer modified electrode, we considered that the 1monolayer would recognize the presence or absence of the carboxyl group in catecholamines.

Dopamine can be detected selectively in the presence of ascorbate at a gold electrode modified by a $\beta$ cyclodextrin/thioctic acid mixed monolayer [105]. Gold electrode with self-assembled D,L-cysteine grafted $\beta$ cyclodextrin sulfonic acid (Cys- $\beta$-CD-SO3) layer was also used to investigate the electrochemical behavior of dopamine [106]. The experimental results indicated that the selfassembled Cys- $\beta-\mathrm{CD}-\mathrm{SO}_{3}$ layer modified gold electrode has selective electrochemical response to dopamine with high sensitivity and excellent tolerance of ascorbic acid. Dopamine could be accurately determined in the presence of ascorbic acid. The proposed sensor was successfully applied to the determination of dopamine in human blood serum samples.

The hydrophobic interactions between ferrocenyl compounds, based on the tamoxifen skeleton (ferrocifens), and non-polar molecular architectures, such as cyclodextrin (CD) cavities and unsubstituted n-alkane chains, were investigated in water and alcohol/water mixtures by cyclic voltammetry through three different approaches [107]. In the first one, the organometallic complex was covalently attached to a glassy carbon electrode surface whereas the CD was dissolved in homogeneous solution. The second one consisted in preparing a self-assembled monolayer of a mixture of synthesized per-6-thio- $\beta-C D$ and of pentanethiol chains at a gold electrode surface, whereas the ferrocifen complex was initially present in solution. In the third approach, the gold electrode surface was modified only with alkane thiol monolayers having various lengths. As expected, the complexation between the ferrocene moiety of the tamoxifen derivative and the CD cavity became stronger as the solvent polarity increased. Interestingly, two different electrochemical behaviors could be evidenced for the neutral starting complex and for the electrogenerated cationic ferrocenium derivative owing to their different polarities. Importantly, the reduction process of the cationic complex followed a distinct behavior on adsorbed CDs and on alkane chains. Notably, the presence of two aromatic rings in the ferrocenyl structure proved to favor its facile penetration through short alkyl chains $\mathrm{C}_{\mathrm{n}} \mathrm{H}_{2 \mathrm{n}+1}, \mathrm{n} \leq 5$. For much longer chains $(16 \leq \mathrm{n}<5)$ a faradaic oxidation current was still observed for ferrocifen though progressively diminished.
Screen-printed carbon-based electrodes modified with thin films of the condensation polymers of $\beta$-cyclodextrin ( $\beta$ CDP) or carboxymethylated $\beta$-cyclodextrin $(\beta$-CDPA) were used as electrochemical sensors for determination of tricyclic antidepressive drugs [108]. The azepine and phenothiazine antidepressive drugs were determined by using a simple twostep procedure developed which comprised a preconcentration step followed by the differential pulse voltammetry quantification. The accumulation properties of the $\beta$-CDPA film appeared to be favorable as compared to those of the $\beta$-CDP film. A sensor featuring the $\beta$-CDPA film-modified electrode was applied successfully for the antidepressant determination in a model serum.

Accumulating properties of thin films of condensation polymers of $\beta$-cyclodextrin ( $\beta$-CDP) and carboxymethylated $\beta$-cyclodextrin ( $\beta$-CDPA) were compared with respect to the selected azepine and phenothiazine type antidepressive drugs [109] by using simultaneous measurements of cyclic voltammetry and piezoelectric microgravimetry at an electrochemical quartz crystal microbalance. At $\mathrm{pH}$ 7.4, the drug accumulation by the film of $\beta$-CDPA in its anionic, i.e., cation-exchange, form was much higher than that of the $\beta$ CDP nonionic film. This favorable property of the $\beta$-CDPA film was due to concurrent effects of the supramolecular complex formation between the $\beta$-CD inclusion sites of the polymer and drug molecules as well as ion exchange of cationic drugs at the carboxymethyl deprotonated groups.

$\mathrm{N}$-Acetyltyramine was synthesized and electropolymerized together with a negatively charged sulfobutylether$\beta$-cyclodextrin on a boron-doped diamond (BDD) electrode followed by the electropolymerization of pyrrole to form a stable and permselective film for selective dopamine detection [110]. The selectivity and sensitivity of the formed layer-by-layer film was governed by the sequence of deposition and the applied potential. The modified BDD electrode exhibited rapid response to dopamine within 1.5-2 $\mathrm{s}$ and a low detection limit of 4-5 $\mathrm{nM}$ with excellent reproducibility. Electroactive interferences caused by 4dihydroxyphenylalanine, 3,4-dihydroxyphenylacetic acid, ascorbic acid, and uric acid were completely eliminated, whereas the signal response of epinephrine and norepinephrine was significantly suppressed by the permselective film.

A glassy carbon electrode surface was modified with an electropolymerized film made of pyrrole and $\beta$-cyclodextrin $1: 1$, exhibits interesting electrocatalytic activity toward the electrochemical oxidation of neurotransmitters such as dopamine (DA) and norepinephrine (NE) [111]. Wellresolved and reversible cyclic voltammograms (CVs) were obtained for these organic compounds. The diffusion coefficients D for the studied molecules were determined by means of the measurement of the effect of the scan rate on the CVs of the neurotransmitters. All the results showed that the electron transfer was predominantly diffusion controlled at the conducting polymer/solution interface. Interference phenomenon due to ascorbic acid (AA) toward the neurotransmitters was also investigated. The novel modified electrodes presented capability to resolve perfectly the AA and neurotransmitters oxidation peaks. This performance could be achieved even at a concentration 20 times higher than the neurotransmitters. 
A procedure for the determination of dopamine in large excess of ascorbate using $\alpha$-cyclodextrin modified gold electrode has been proposed [112]. Dopamine incorporated in the $\alpha$-cyclodextrin sites anchored to the electrode surface was found to provide electrochemical contact of the electrode with the solution-resident dopamine. Dopamine present in the $\alpha$-cyclodextrin cavities has different properties compared to dopamine in the bulk buffer solution and can act as a mediator for the dopamine molecules diffusing to the electrode. This unique mediation effect led to improvement of the sensitivity of dopamine determination using the $\alpha$ cyclodextrin modified electrode.

A highly selective and sensitive electrochemical sensor modified with carboxymethylated $\beta$-cyclodextrin (CM- $\beta$ CDP) polymer film was fabricated for the determination of dopamine (DA) in the presence of ascorbic acid (AA) [113]. The electrochemical behavior of DA and AA at the chemically modified electrode was investigated by cyclic voltammetry $(\mathrm{CV})$ and differential pulse voltammetry. The response mechanism of CM- $\beta$-CDP film for DA was based on the combination of electrostatic and inclusion interaction of CM- $\beta$-CDP for DA, which was distinguished from the response mechanism of the charged polymer film modified electrode that only relied upon the electrostatic interaction between charged polymer film and DA (or AA) to realize the separation of overlapping peak potential of DA and AA. The CM- $\beta$-CDP film showed preferable analytical performance characteristics in catalytic oxidation of DA compared with the $\beta$-CDP polymer film. Under optimized conditions, it was feasible for the electrode modified with the CM- $\beta$-CDP film to selectively determine DA in the presence of a large excess of AA. This electrochemical sensor showed excellent sensitivity, repeatability, stability, and recovery for the determination of DA.

A functionalized stable film of poly-3-methylthiophene combined with $\gamma$-cyclodextrin $(\mathrm{P} 3 \mathrm{MT} / \gamma-\mathrm{CD})$ in tetrabutylammonium hexafluorophosphate/acetonitrile solution has been prepared and used as a sensor for dopamine, 1-dopa and chlorpromazine [114]. A potentiostatic mode was employed for the film growth. Cyclic voltammetry and electrochemical impedance spectroscopy were used for the characterization of the new film. The resulting conducting polymer sensor offered interesting analytical performances as fast and linear responses towards the studied compounds with low detection limits of $2 \times 10^{-7}, 10^{-6}$, and $10^{-7} \mathrm{M}$, respectively, and simultaneous detection and well-resolved signals between the compounds of interest and ascorbic acid. Optimization of parameters such as interference effect, perm-selectivity, and mechanical stability of the sensor were discussed.

A $\beta$-cyclodextrin ( $\beta$-CD)-based sensor has been developed for a simple and sensitive determination of rifampicin (RIF) [115]. $\beta-C D$ was fixed onto a Pt electrode by means of pyrrol electropolymerization. RIF was deposited on the surface of the modified electrode through complex formation and quantified amperometrically. The experimental variables were optimized using an experimental design, taking into account all the possible interactions between them. Under these conditions, repeatability, reproducibility and stability of the modified electrode have been analysed. Interferences from other anti-TB compounds were investigated. The modified electrode was applied to the
RIF determination in pharmaceutical preparations and biological samples.

A film of polypyrrole/ $\gamma$ cyclodextrin (PPY/ $\gamma \mathrm{CD})$ was synthesized at a gold electrode and used for the electrochemical detection of neurotransmitters [116]. The film was synthesized by the simple electropolymerization of a 1:1 mixture of $\gamma \mathrm{CD}$ and pyrrole monomer in aqueous solutions and electrochemical impedance spectroscopy (EIS) was used to characterize its electrical properties. The $\mathrm{PPY} / \gamma \mathrm{CD}$ films exhibit interesting properties such as a wider potential range for electroanalytical exploration that yields to easier and improved electrochemical detection of neurotransmitters such as dopamine, L-dopa, epinephrine, norepinephrine, and isoproterenol. Well resolved and reversible cyclic voltammograms (CVs) of these organic compounds could be obtained easily at the modified electrode with a negative shift of their oxidation potentials as compared with the response at bare gold electrodes. The plot of the neurotransmitters' catalytic currents $v s$ their concentrations gave good linear relationship. Attempts to use the PPY $/ \gamma \mathrm{CD}$ sensor on real human serum for L-dopa exploration yield encouraging data. The preliminary results showed that the obtained modified electrode is mechanically stable and features good permselectivity toward interferences such as ascorbic acid at a concentration of more than 500fold for some neurotransmitters. Cyclodextrin- polypyrrole (CD-Ppy) was also fabricated on gold electrodes and used as sensors to detect concentrations of the muscle relaxant rocuronium bromide [117], where concentrations of $1 \mathrm{ppm}$ could be detected.

The feasibility of an inclusion complex between a selfassembled $\beta$-cyclodextrin $(\beta-C D)$-derivative monolayer $\beta$ CD-SAM with some steroids such as cortisol and cortisone has been evaluated [118]. The selectivity of the $\beta$-CD host surface was verified by using electroactive species permeable and impermeable in the $\beta-C D$ cavity. The redox probe was selected according to its capacity to permeate the $\beta-C D$ monolayer and its electrochemical behavior. The formation constant of the surface host-guest by $\beta$-CD-SAM and the steroids under study was calculated.

A new alternative for the electrochemical determination of catecholamines based on $\beta$-cyclodextrin-Sonogel-Carbon electrodes has been reported [119]. The incorporation of $\beta$ $\mathrm{CD}$ and graphite in the preparation of the Sonogel-Carbon material led to a modification of the electrode surface properties which causes a significant increase in the oxidation peak current of biomolecules such as dopamine, 1epinephrine, d,l-norepinephrine and catechol. This phenomenon might be attributed to the formation of an inclusion complex between $\beta-\mathrm{CD}$ and the catecholamines. The amount of $\beta-C D$ necessary to form the Sonogel electrode was studied and optimization of electrochemical parameters, perm selectivity and mechanical stability of the sensor are discussed. Cyclic voltammetry (CV) and Adsorptive differential pulse voltammetry (AdDPV) measurements were used to explore the electrochemical behaviour of the electrode versus the quoted catecholamines. The $\beta$-CD-Sonogel-Carbon electrode offers fast and linear responses towards dopamine, norepinephrine, epinephrine and catechol, with good and low detection limits: 0.164 , $0.294,0.699$ and $0.059 \mu \mathrm{M}^{-1}$, respectively. 
A simple, accurate and sensitive voltammetric method for determination of Anagrelide (ANG) using cyclodextrin modified carbon paste electrode (CDMCPE) has been developed [120]. CDMCPE exhibited significantly increased sensitivity and selectivity for ANG compared to bare carbon paste electrode. The proposed method has been successfully applied for the determination of ANG in spiked serum sample, urine samples and pharmaceutical formulations.

Carbon paste electrodes modified with $\beta$-cyclodextrin have been investigated for the differential pulse voltammetric determination of the tricyclic antidepressants imipramine, trimipramine and thioridazine [121]. Host-guest interaction was studied and experimental conditions of the working procedure were optimized. The accumulation ability of $\beta$-cyclodextrin leads to detection limits down to nanomolar concentrations for $120 \mathrm{~s}$ accumulation. The electrode was applied to the determination of imipramine and thioridazine in pharmaceuticals.

The reduced $\mathrm{C}_{60}$-[dimethyl-( $\beta$-cyclodextrin $\left.)\right]_{2}$ and Nafion chemically modified electrode (CME) has been shown to catalyze the electrochemical response of norepinephrine (NE) at an electrode [122]. A pair of well-defined redox waves was obtained and the standard rate constant was calculated. Results indicated that reduced CME acted as a promoter to the electron transfer of NE.

Carbon paste electrodes modified with $\beta$-cyclodextrin have been investigated for voltammetric determination of nitrendipine [123]. The immobilization of the $\beta$-cyclodextrin on the carbon paste led to a modification of the electrode surface that caused a significant increase in the peak current of the nitrendipine reduction, probably due to formation of an inclusion complex between $\beta$-cyclodextrin and nitrendipine. This property was used with analytical purposes by developing a stripping differential pulse voltammetric (SDPV) method to determine nitrendipine.

The electrochemical behavior of sparfloxacin [124], ofloxacin (OF), norfloxacin (NF), gatifloxacin (GF), and lomefloxacin (LF) [125] at $\beta$-cyclodextrin modified carbon paste electrode (CDMCPE) has been studied. Compared with bare carbon paste electrode $(\mathrm{CPE})$, the $\beta$-cyclodextrin modified carbon paste electrode exhibited a marked enhancement of current response of Sparfloxacin, OF, NF, GF, and LF. These increases in the peak currents from the techniques $\mathrm{CV}$ and DPV were attributed to the complex formation of quinone group of the drugs with $\beta$-cyclodextrin. Cyclic voltammetric (CV) studies indicated that the process was irreversible and adsorption controlled. The experimental parameters, which influence the peak current responses of Sparfloxacin, OF, NF, GF, and LF were studied. The interference of metal ions in the peak current response for OF, NF, GF, and LF was also studied. The modified electrode exhibited good sensitivity and stability. The proposed method was applied to the determination of Sparfloxacin, OF, NF, GF, and LF in both commercially available drugs and spiked human urine samples.

Osteryoung square wave cathodic or anodic voltammetry has been used for the determination of $(+)$-catechin $(\mathrm{CAT})$ at physiological $\mathrm{pH}$ using $\beta$-cylcodextrin modified carbon paste electrode [126]. A reproducible and reliable method using cathodic and anodic voltammetry was achieved. The proposed method was applied successfully for the determination of CAT in commercial tea samples with acceptable recovery. The extraction of CAT from commercial tea samples was rather simple, making it suitable for studies with a large number of commercial tea samples giving high accuracy of the proposed method.

The redox-sensing abilities of a synthesized conjugate, Ferrocene with a $\beta$-cyclodextrin unit bound to one or both cyclopentadienyl rings through the secondary face, towards bile salts (sodium cholate, deoxycholate, and chenodeoxycholate) has been evaluated using electrochemical methods (cyclic and differential pulse voltammetry) [127]. These techniques allowed the determination of stability constants, mode of inclusion, and diffusion coefficients for complexes formed with the neutral and, in some cases, the oxidized states of the ferrocenyl conjugates.

A simple method based on a combination of multi-walled carbon nanotubes with incorporated $\beta$-cyclodextrin $(\beta-\mathrm{CD}$ MWNTs) and a polyaniline (PANI) film-modified glassycarbon (GC) electrode has been successfully developed for determination of dopamine (DA) in the presence of ascorbic acid (AA) [84]. The acid-treated MWNTs with carboxylic acid functional groups promoted the electron-transfer reaction of DA and inhibited the voltammetric response of AA. Sensitive detection of DA was further improved by the preconcentration effect of formation of a supramolecular complex between $\beta-C D$ and DA. Therefore, the analytical response of the $\beta$-CD-MWNTs/PANI film to the electrochemical behavior of DA was better than that of a MWNTs/PANI film, a PANI film, or a bare glassy carbon electrode (GCE). Interference from AA was effectively eliminated and the sensitivity, selectivity, stability, and reproducibility of the electrodes were excellent for determination of DA.

An electrochemical sensor modified with multi-walled carbon nanotubes/ $\beta$-cyclodextrin (MWNTs/ $\beta$-CD) film was fabricated for the determination of rutin [85]. The electrochemical behavior of rutin at the chemically modified electrode was investigated by cyclic voltammetry (CV). The response mechanism of MWNTs/ $\beta$-CD film for rutin was based on the inclusion interaction of $\beta-\mathrm{CD}$ for rutin. The MWNTs/ $\beta-C D$ film showed preferably analytical performance characteristics in electrocatalytic oxidation and reduction for rutin compared with the MWNTs film and bare glassy carbon electrode (GCE). This electrochemical sensor showed excellent sensitivity, selectivity, stability and recovery for the determination of rutin in urine samples.

The electrochemical behavior of sodium cholate (CA) and deoxycholate (DCA) was investigated on ITO electrodes coated with $\beta$-cyclodextrin $(\beta-C D)$ modified multi-walled carbon nanotubes (MWNTs) in aqueous solution [88]. $\beta-\mathrm{CD}$ modified MWNTs (MWNT-CDs) showed electrocatalytic effect on the reduction of $\mathrm{CA}$, while electrochemical response of DCA was not observed. To further understand the mechanism of the electrochemical process, the electrochemical behavior of CA and DCA on bare ITO electrode and the electrode modified with MWNTs possessing carboxyl groups (MWNT-COOHs) was also discussed. The results indicated that the electrochemical response of CA could be improved through the use of carbon 
nanotubes. The introduction of cyclodextrin moieties enhanced the selectivity of the electrodes to CA and DCA.

A GCE modified with MWNTs and $\beta$-cyclodextrin ( $\beta$ CD) complex (MWNTs $+\beta$-CD/GCE) was prepared for comparing its electrochemical behavior with those modified with multi-wall carbon nanotubes (MWNTs) and succinoglycan monomers and electrochemically characterized for monitoring quercetin that was dispersed in an aqueous electrolyte solution [87]. Square wave voltammograms showed about sixteen times of higher sensitivity as compared with the measured sensitivity of the (MWNTs $+\beta-\mathrm{CD}) / \mathrm{GCE}$.

The selectivity of the succinyl- $\beta$-CD-modified, multiwall carbon nanotube (MWNT)-coated, glassy carbon electrode to quercetin and rutin was investigated [86]. ${ }^{1} \mathrm{H}$ NMR and MALDI-MS data confirmed molecular structure of the synthesized succinyl- $\beta-C D$. As a dopant in carboxylated MWNT-modified electrode, succinyl- $\beta-C D$ clearly separated the peak potential $\left(E_{p}\right)$ of quercetin from that of rutin. The measured peak potential separation $\left(\Delta \mathrm{E}_{\mathrm{p}}\right)$ was $110 \mathrm{mV}$. More favorable complexation between succinyl- $\beta-C D$ and quercetin may enhance relative selectivity to quercetin of the (succinyl- $\beta-C D+$ MWNT)/GCE in quercetin-rutin mixture as compared to the $\beta$-CD-modified GCE.

Multilayer films of multiwalled carbon nanotubes (MWCNTs) with $\beta$-CD have been assembled on glassy carbon (GC) electrode and studied with respect to the electrocatalytic activity toward dopamine (DA) [89]. Two steps have been used for the electrode modification: first, MWCNTs interacted with $\beta$-cyclodextrin $(\beta-C D)$ with the aid of sonication to form $\beta$-CD-MWCNTs nanocomposite, then the $\beta$-CD-MWCNTs nanocomposite was assembled on GC electrode using layer-by-layer (LBL) method based on electrostatic interaction of positively charged biopolymer chitosan and negatively charged MWCNTs. The assembled $\beta$-CD-MWCNTs multilayer films were characterized by scanning electron microscopy (SEM) and cyclic voltammetry. Compared with the MWCNTs multilayer films without $\beta-C D$, the MWCNTs multilayer films with $\beta-C D$ possesses a much lower capacitive background current and higher electrocatalytic activity in phosphate buffer, which was ascribed to the relatively compact three-dimensional structure of the MWCNTs multilayer films with $\beta-C D$ and the excellent molecule recognition function of $\beta-C D$.

The application of lipophilic $\beta$-CDs as ionophores for sensing acetylcholine chloride using an amperometric biosensor has been described [128]. Amperometric biosensors were assembled by modifying screen-printed electrodes with a ferrocenyl charge shuttle, enzymes (horseradish peroxidase, choline oxidase and/or acetylcholine esterase) and a thin film comprising a polyurethane matrix, 2,3,6-triethyl- $\beta-\mathrm{CD}$, a plasticizer and a large anionic salt. The resulting sensor, which was capable of detecting subpicomolar levels of acetylcholine, was highly specific and was stable to storage in air and in solution. Interference from endogenous electroactive compounds was minimal.

A supramolecular approach was used for adsorbing a monolayer of adamantane-modified phenylalanine dehydrogenase on $\beta$-cyclodextrin-coated Au electrodes [129]. The reversible nature of this immobilization approach was confirmed. The enzyme electrode showed a linear amperometric response with a lower detection limit.

\section{CONCLUSIONS}

Because of their complexation ability with various pharmaceutical compounds, cyclodextrins are continued to be the subject of intensive electrochemical research including both their interactions in solution and in thin films attached to the electrode surfaces. Electrochemical measurements are often employed to provide information on the selectivity and stability of the complexes and to explain the chemical reactions taking place inside the cavity and to rationalize the catalytic properties of the $\mathrm{CD}$ microenvironment. CDs can be immobilized on the working electrodes in ways which are typically used for the preparation of chemically modified electrodes. Preparation of CDs modified electrodes promises new electrochemical sensors and remains a very active field of research for applications in pharmaceutical analysis.

\section{REFERENCES}

[1] Hamilton, L.M.; Kelly, C.T.; Fogarty, W.M. Raw starch degradation by the non-raw starch-adsorbing bacterial alpha amylase of Bacillus sp. IMD 434. Carbohydr. Res., 1998, 314, 251.

[2] Rendleman Jr, J.A. Enhancement of cyclodextrin production through use of debranching enzymes. Biotechnol. Appl. Biochem., 1997, 26, 51 .

[3] Kim, T.J.; Kim, B.C.; Lee, H.S. Production of cyclodextrin using raw corn starch without a pretreatment. Enzyme Microb. Technol., 1997, 20, 506 .

[4] Flaschel, E.; Landert, J.P.; Spiesser, D.; Renken, A. The production of $\alpha$-cyclodextrin by enzymatic degradation of starch. Ann. N. Y. Acad. Sci., 1984, 434, 70.

[5] Szejtli, J. Past, present, and future of cyclodextrin research. Pure Appl. Chem., 2004, 76, 1825.

[6] Szejtli, J. Cyclodextrins and Their Inclusion Complexes, Akademiai Kiado: Budapest, 1982.

[7] Inoue, Y.; Hakushi, T.; Liu, Y.; Tong, L.H.; Shen, B.J.; Jin, D.S. Thermodynamics of molecular recognition by cyclodextrins. 1. Calorimetric titration of inclusion complexation of naphthalenesulfonates with $\alpha-, \beta-$, and $\gamma$-cyclodextrins: Enthalpyentropy compensation. J. Am. Chem. Soc., 1993, 115, 475.

[8] Manning, C.M.; Patel, K.; Borchardt, R.T. Stability of protein pharmaceuticals. Pharm. Res., 1989, 6, 903.

[9] Saenger, W. In Structural Aspects of Cyclodextrins and their Inclusion Complexes; Atwood, J.L.; Davies, J.E.D; MacNicol, D.D., Eds.; Academic Press: London, 1984, Vol. 2, pp. 231-259.

[10] Funasaki, N.; Ishikawa, S.; Neya, S. Advances in physical chemistry and pharmaceutical applications of cyclodextrins. Pure Appl. Chem., 2008, 80, 1511.

[11] Irie, T.; Uekama, K. Pharmaceutical applications of cyclodextrins. III. Toxicological issues and safety evaluation. J. Pharm. Sci., 1997, 86, 147.

[12] Jones, S.P.; Grant, D.J.W.; Hadgraft, J.; Parr, G. Cyclodextrins in the pharmaceutical sciences. II. Pharmaceutical, biopharmaceutical, biological and analytical aspects, and applications of cyclodextrin and its inclusion compounds. Acta Pharm. Technol., 1984, 30, 263.

[13] Loftsson, T.; Brewster, M.E. Pharmaceutical applications of cyclodextrins. 1. Drug solubilization and stabilization. J. Pharm. Sci., 1996, 85, 1017.

[14] Loftsson, T.; Duchêne, D. Cyclodextrins and their pharmaceutical applications. Int. J. Pharm., 2007, 329, 1.

[15] Rajewski, R.A.; Stella, V.J. Pharmaceutical applications of cyclodextrins. 2. In vivo drug delivery. J. Pharm. Sci., 1996, 85, 1142.

[16] Singh, I.; Aboul-Enein, H.Y. Pharmaceutical applications of cyclodextrins. FABAD J. Pharm. Sci., 2005, 30, 214.

[17] Uekama, K. Pharmaceutical applications of methylated cyclodextrins. Pharm. Int., 1985, 6, 61. 
[18] Uekama, K. Recent aspects of pharmaceutical application of cyclodextrins. J. Inclusion Phenom., 2002, 44, 3.

[19] Uekama, K. Pharmaceutical application of cyclodextrins as multifunctional drug carriers. Yakugaku Zasshi, 2004, 124, 909.

[20] Bekers, O.; Uijtendaal, E.V.; Beijnen, J.H.; Bult, A.; Underberg, W.J.M. Cyclodextrins in the pharmaceutical field. Drug Dev. Ind. Pharm., 1991, 17, 1503.

[21] Szejtli, J. Cyclodextrin in drug formulations Part I. Pharm. Technol. Int., 1991, 3, 15.

[22] Matsuda, H.; Arima, H. Cyclodextrins in transdermal and rectal delivery. Adv. Drug Deliv. Rev., 1999, 36, 81.

[23] Szente, L.; Szejtli, J. Highly soluble cyclodextrin derivatives: Chemistry, properties, and trends in development. Adv. Drug Deliv. Rev., 1999, 36, 17 .

[24] Ferancová, A.; Labuda, J. Cyclodextrins as electrode modifiers. Anal. Bioanal. Chem., 2001, 370, 1 .

[25] Ferancová, A.; Labuda, J.; Barek, J.; Zima, J. Cyclodextrins as supramolecular complex agents in electroanalytical chemistry: review 1995-2001. Chem. Listy, 2002, 96, 856

[26] Bersier, P.M.; Bersier, J.; Klingert, B. Electrochemistry of cyclodextrins and cyclodextrin inclusion complexes. Electroanalysis, 1990, 3, 443.

[27] Dang, X.-J.; Tong, J.; Li, H.-L. The electrochemistry of the inclusion complex of anthraquinone with/3-cyclodextrin studied by means of OSWV. J. Inclusion Phenom. Mol. Recognit. Chem., 1996, 24, 275.

[28] Matsue, T.; Osa, T.; Evans, D.H. Determination of some physical constants of cyclodextrin complexes by electrochemical methods. J. Inclusion Phenom., 1984, 2, 547.

[29] Steed, J.W.; Atwood, J. L. Supramolecular Chemistry, J. Wiley \& Sons: Chichester: New York, 2000.

[30] Kaifer, A.E. in Comprehensive Supramolecular Chemistry, Atwood, J.L.; Davies, J.E.D.; MacNicol, D.D.; Vőgtle, F., Eds.; Pergamon: Oxford, 1996; pp. 499-535.

[31] Maeda, Y.; Fukuda, T.; Yamamoto, H.; Kitano, H. Regio- and stereoselective complexation by a self-assembled monolayer of thiolated cyclodextrin on a gold electrode. Langmuir, 1997, 13, 4187.

[32] Fukuda, T.; Maeda, Y.; Kitano, H. Stereoselective inclusion of DOPA derivatives by a self-assembled monolayer of thiolated cyclodextrin on a gold electrode. Langmuir, 1999, 15, 1887.

[33] Connors, K.A. The stability of cyclodextrin complexes in solution. Chem. Rev., 1997, 97, 1325 .

[34] Rekharski, M.V.; Inoue, Y. Complexation thermodynamics of cyclodextrins. Chem. Rev., 1998, 98, 1875.

[35] Aboul-Enein, H.Y.; Stefan, R.I.; Van Staden, J.F. Potentiometric enantioselective membrane electrode for s-enalapril assay. Analusis, 1999, 27, 53.

[36] Bazylak, G.; Nagels, L.J. Potentiometric detection of betaadrenolytic and beta-adrenergic drugs in HPLC systems. Postepy Hig. Med. Dosw., 2005, 59, 554

[37] Kelani, K.M. Selective potentiometric determination of zolpidem hemitartrate in tablets and biological fluids by using polymeric membrane electrodes. J. AOAC Int., 2004, 87, 1309.

[38] Koch, H.; Groning, R.; Ebel, J.; Grau, P.; Ahlers, B.; Decker, M.; Haase, W.; Cammann, K. Electroanalytical investigations concerning the inclusion of chloramphenicol succinate sodium in cyclodextrins. Pharmazie, 1994, 49, 192.

[39] Kopecký, F.; Vojteková, M.; Kováčová, S.; Juríčeková, M. Inclusion complexation of carbethopendecinium bromide with some $\alpha$ - and $\beta$-cyclodextrins studied by potentiometry with membrane electrodes. Collect. Czech. Chem. Commun., 2004, 69, 384.

[40] Kopecký, F.; Vojteková, M.; Vrana, M.; Č́žová, K. Potentiometric study of carbisocaine micellization and inclusion complexation with $\alpha$-cyclodextrin, $\beta$-cyclodextrin, methyl- $\beta$-cyclodextrin, and (hydroxypropyl)- $\beta$-cyclodextrin. Collect. Czech. Chem. Commun., $\mathbf{2 0 0 2}, 67,245$

[41] Lima, J.L.F.; Montenegro, M.C.B. Dopamine ion-selective electrode for potentiometry in pharmaceutical preparations. Mikrochim. Acta, 1999, 131, 187 .

[42] Mostafa, G.A.E.; Abbas, M.N. PVC membrane sensor for potentiometric determination of atropine in some pharmaceutical formulations. Instrum. Sci. Technol., 2008, 36, 209.
[43] Ozoemena, K.I.; Stefan, R.I.; Staden, J.F.V.; Aboul-Enein, H.Y Enantioanalysis of S-perindopril using different cyclodextrin-based potentiometric sensors. Sensor Actuat. B-Chem., 2005, 105, 425.

[44] Pimenta, A.M.; Araújo, A.N.; Montenegro, M.C.B. Simultaneous potentiometric and fluorimetric determination of diclofenac in a sequential injection analysis system. Anal. Chim. Acta, 2002, 470, 185.

[45] Rizk, N.M.H.; Abbas, S.S.; El-Sayed, F.A.; Abo-Bakr, A. Novel ionophore for the potentiometric determination of cetirizine hydrochloride in pharmaceutical formulations and human urine. Int. J. Electrochem. Sci., 2009, 4, 396.

[46] Stefan van Staden, R.I.; Rat'ko, A.A. Enantioselective, potentiometric membrane electrodes based on cyclodextrins: Application for the determination of R-baclofen in its pharmaceutical formulation. Talanta, 2006, 69, 1049.

[47] Stefan-Van Staden, R.I.; Holo, L.; Moeketsi, B.; Van Staden, J.F ; Aboul-Enein, H.Y. Enantioselective determination of R-clenbuterol using an enantioselective, potentiometric membrane electrode based on a $\beta$-cyclodextrin derivative. Instrum. Sci. Technol., 2009, $37,189$.

[48] Jalali, F.; Maghooli, R. Potentiometric determination of trace amounts of amantadine using a modified carbon-paste electrode. Anal. Sci., 2009, 25, 1227.

[49] Kataky, R.; Toth, K.; Palmer, S.; Feher, Z. A study of the effect of proteins and endogenous cations on a lipophilic $\beta$-cyclodextrinbased potentiometric lidocaine sensor using discrete solution and flow-injection analysis. Talanta, 1999, 50, 939.

[50] Takisawa, N.; Hall, D.G.; Wyn-Jones, E.; Brown, P. The construction and characteristics of drug-selective electrodes. Applications for the determination of complexation constants of inclusion complexes with $\alpha$ - and $\beta$-cyclodextrins including a kinetic study. J. Chem. Soc., Faraday Trans. 1, 1988, 84, 3059.

[51] Valsami, G.N.; Koupparis, M.A.; Macheras, P.E. Complexation studies of cyclodextrins with tricyclic antidepressants using ionselective electrodes. Pharm. Res., 1992, 9, 94.

[52] Valsami, G.N.; Macheras, P.E.; Koupparis, M.A. Binding studies of ions with cyclodextrins using ion-selective electrodes. J. Pharm. Sci., 1990, 79, 1087.

[53] Wang, X.M.; Chen, H.Y.; Li, S.Y.; Wang, J.D. Studies of an inclusion complex of a redox-active barbiturate with $\beta$ cyclodextrin. Anal. Chim. Acta, 1994, 290, 349.

[54] Kuchekar, B.S.; Vakil, J.R. Characterisation of menadione- $\beta$ cyclodextrin inclusion complex. Indian Drugs, 1994, 31, 282

[55] Nie, M.Y.; Wang, Y.; Li, H.L. Electrochemical and spectral properties of phenylhydrazine in the presence of $\beta$-cyclodextrin. Pol. J. Chem., 1997, 71, 816.

[56] Gao, Z.; Li, H. Spectroscopic and electrochemical studies of phenylhydrazine- $\alpha$-cyclodextrin inclusion complex and its adsorption behaviors. Acta Phys.-Chim. Sin., 1999, 15, 1009.

[57] Dang, X.J.; Nie, M.Y.; Tong, J.; Li, H.L. Inclusion of the parent molecules of some drugs with $\beta$-cyclodextrin studied by electrochemical and spectrometric methods. J. Electroanal. Chem., 1998, 448,61 .

[58] Lu, C.S.; Ren, X.M.; Hu, C.J.; Zhu, H.Z.; Meng, Q.J. The inclusion compound of a new ionizable derivative of $\beta$-cyclodextrin with ferrocenium drug. Chem. Pharm. Bull., 2001, 49, 818 .

[59] Shehatta, I.S.; Ibrahim, M.S. Binding of anti-inflammatory drug indomethacin with cyclodextrin and DNA: Solubility, spectroscopic, and voltammetric studies. Can. J. Chem., 2001, 79, 1431

[60] Shehatta, I.S.; Ibrahim, M.S.; Sultan, M.R. The antimicrobial nalidixic acid as a probe for molecular recognition of $\alpha$ - and $\beta$ cyclodextrins. Can. J. Chem., 2002, 80, 1313 .

[61] Song, J.F.; He, P.; Wang, F.M. Study on the inclusion complex of irisquinone with $\beta$-cyclodextrin. Yaохие Xиebao, 2002, 37, 963.

[62] Gao, Z.N.; Wen, X.L.; Li, H.L. Study of the inclusion complexes of catecholamines with $\beta$-cyclodextrin by cyclic voltammetry. Pol. $J$. Chem., 2002, 76, 1001.

[63] Ibrahim, M.S.; Shehatta, I.S.; Al-Nayeli, A.A. Voltammetric studies of the interaction of lumazine with cyclodextrins and DNA. J. Pharm. Biomed. Anal., 2002, 28, 217.

[64] Zhou, C.; Luo, C.; Shou, C.; He, L.; Li, H.; Yu, J. Studied on the cyclodextrins-hexamethylenetetramine inclusion complex by electrochemical method and its analytical applications. Fenxi Ниахие, 2003, 31, 566. 
[65] Yang, G.J.; Xu, J.J.; Chen, H.Y.; Leng, Z.Z. Studies on the interaction between rutin and DNA in the absence and presence of $\beta$-cyclodextrin by electrochemical and spectroscopic methods. Chin. J. Chem., 2004, 22, 1325.

[66] de Abreu, F.C.; Ferreira, D.C.M.; Goulart, M.O.F.; Buriez, O.; Amatore, C. Electrochemical activation of $\beta$-lapachone in $\beta$ cyclodextrin inclusion complexes and reactivity of its reduced form towards oxygen in aqueous solutions. J. Electroanal. Chem., 2007, $608,125$.

[67] Yáñez, C.; Zamora, C.; Jara, P. In Electrochemical Study of Inclusion Complexes Cyclodextrin/Steroids, Proceedings of 208th Meeting of The Electrochemical Society; Los Angeles, CA, October 16-21, 2005, p. 2137.

[68] Yañez, C.; Basualdo, J.; Jara-Ulloa, P.; Squella, J.A. Inclusion complexes of estrone and estradiol with $\beta$-cyclodextrin: Voltammetric and HPLC studies. J. Phys. Org. Chem., 2007, 20, 499.

[69] Yañez, C.; Basquinzay, R. Chronocoulometry diffusion coefficients as a measure of cyclodextrin-estradiol complex association. $J$. Electroanal. Chem., 2008, 622, 242.

[70] Temerk, Y.M.; Ibrahim, M.S.; Kotb, M. Voltammetric and spectroscopic studies on binding of antitumor Morin, Morin- $\mathrm{Cu}$ complex and Morin- $\beta$-cyclodextrin with DNA. Spectrochim. Acta A Biomol. Spectrosc., 2009, 71, 1830.

[71] Nagase, S.; Kataoka, M.; Naganawa, R.; Komatsu, R.; Odashima, K.; Umezawa, Y. Voltammetric anion responsive sensors based on modulation of ion permeability through Langmuir-Blodgett films containing synthetic anion receptors. Anal. Chem., 1990, 62, 1252.

[72] Chmurski, K.; Bilewicz, R.; Jurczak, J. Monolayer behavior of [6deoxy-6-S-phenyl]- $\alpha-, \beta$-, and $\gamma$-cyclodextrins at the air-water interface. Langmuir, 1996, 12, 6114.

[73] Wazynska, M.; Temeriusz, A.; Chmurski, K.; Bilewicz, R.; Jurczak, J. Synthesis and monolayer behavior of amphiphilic per(2,3-di-O-alkyl)- $\alpha$ - and $\beta$-cyclodextrins and hexakis(6-deoxy-6thio-2,3-di-O-pentyl)- $\alpha$-cyclodextrin at an air-water interface. Tetrahedron Lett., 2000, 41, 9119.

[74] LeBras, Y.; Salle, M.; Leriche, P.; Mingotaud, C.; Richomme, P.; Moller, J. Functionalization of the cyclodextrin platform with tetrathiafulvalene units: an efficient access towards redox active Langmuir-Blodgett films. J. Mater. Chem., 1997, 7, 2393

[75] Kawabata, Y.; Matsumoto, M.; Tanaka, M.; Takahashi, H.; Irinatsu, Y.; Tamura, S.; Tagaki, W.; Nakahara, H.; Fukuda, K. Formation and deposition of monolayers of amphiphilic $\beta$ cyclodextrin derivatives. Chem. Lett., 1986, 15, 1933.

[76] Zhang, P.; Parrot-Lopez, H.; Tchoreloff, P.; Baszkin, A.; Ling, C.C.; de Rango, C.; Coleman, A.W. Self-organizing systems based on amphiphilic cyclodextrin diesters. J. Phys. Org. Chem., 1992, 5, 518.

[77] Parrot-Lopez, H.; Ling, C.C.; Zhang, P.; Baszkin, A.; Albrecht, G.; De Rango, C.; Coleman, A. W. Self-assembling systems of the amphiphilic cationic per-6-amino- $\beta$-cyclodextrin 2,3 di-O-alkyl ethers. J. Am. Chem. Soc., 1992, 114, 5479.

[78] Parazak, D.P.; Khan, A.R.; D’Souza, V.T.; Stine, K.J. Comparison of host-guest Langmuir-Blodgett multilayer formation by two different amphiphilic cyclodextrins. Langmuir, 1996, 12, 4046.

[79] Kunitake, M.; Kotoo, K.; Manabe, O.; Muramatsu, T.; Nakashima, N. Synthesis and spectral characterization of a rotaxane of $\beta$ cyclodextrin threaded by a 4,4'-diaminostilbene. Chem. Lett., 1993, 22, 1033.

[80] Chmurski, K.; Temeriusz, A.; Bilewicz, R. Measurement of ibuprofen binding to mixed monolayers containing $\beta$-cyclodextrin active sites. J. Inclusion Phenom. Macrocycl. Chem., 2004, 49, 187.

[81] Chmurski, K.; Koralewska, A.; Temeriusz, A.; Bilewicz, R. Catalytic Au electrodes based on SAMs of per(6-deoxy-6-thio-2,3di-O- methyl)- $\beta$-cyclodextrin. Electroanalysis, 2004, 16, 1407.

[82] Chmurski, K.; Bilewicz, R.; Jurczak, J. Monolayer behavior of [6deoxy-6-S-phenyl]- $\alpha-, \beta$-, and $\gamma$-cyclodextrins at the air-water interface. Langmuir, 1996, 12, 6114.

[83] Ohira, A.; Ishizaki, T.; Sakata, M.; Taniguchi, I.; Hirayama, C.; Kunitake, M. Formation of the 'nanotube' structure of $\beta$ cyclodextrin on $\mathrm{Au}(\mathrm{III})$ surfaces induced by potential controlled adsorption. Colloids Surf., A, 2000, 169, 27.

[84] Yin, T.; Wei, W.; Zeng, J. Selective detection of dopamine in the presence of ascorbic acid by use of glassy-carbon electrodes modified with both polyaniline film and multi-walled carbon nanotubes with incorporated $\beta$-cyclodextrin. Anal. Bioanal. Chem., 2006, 386, 2087.

[85] He, J.L.; Yang, Y.; Yang, X.; Liu, Y.L.; Liu, Z.H.; Yu, R.Q. $\beta$ Cyclodextrin incorporated carbon nanotube-modified electrode as an electrochemical sensor for rutin. Sensor Actuat. B-Chem., 2006 $114,94$.

[86] Jin, J.H.; Kim, H.; Jung, S. Electrochemical selectivity enhancement by using monosuccinyl $\beta$-cyclodextrin as a dopant for multi-wall carbon nanotube-modified glassy carbon electrode in simultaneous determination of quercetin and rutin. Biotechnol. Lett., 2009, 31, 1739.

[87] Jin, J.H.; Kwon, C.; Park, W.; Kim, S.; Jung, S. Electrochemical characterization of a glassy carbon electrode modified with microbial succinoglycan monomers and multi-wall carbon nanotubes for the detection of quercetin in an aqueous electrolyte. J. Electroanal. Chem., 2008, 623, 142.

[88] Kang, S.Z.; Cui, Z.; Mu, J. Electrochemical behavior of sodium cholate and deoxycholate on an electrode modified with multiwalled carbon nanotubes (MWNTs) linked up with cyclodextrin. Diam. Relat. Mater., 2007, 16, 12.

[89] Kong, B.; Zeng, J.; Luo, G.; Luo, S.; Wei, W.; Li, J. Layer-by-layer assembled carbon nanotube films with molecule recognition function and lower capacitive background current Bioelectrochemistry, 2009, 74, 289.

[90] Petr, A.; Dunsch, L.; Koradecki, D.; Kutner, W. An electron spin resonance (ESR) and simultaneous electrochemical and electron spin resonance (SEESR) spectroscopic study of motion, stability and potential controlled release of radical guests from the $\beta$ cyclodextrin inclusion polymer. J. Electroanal. Chem., 1991, 300, 129.

[91] Koradecki, D.; Kutner, W. Inclusion of the regioisomeric nitrobenzene derivatives and ferrocene guests by $\beta$-cyclodextrin polymer and their transport through the polymer matrix. $J$. Inclusion Phenom. Mol. Recognit. Chem., 1991, 10, 79.

[92] Kutner, W.; Strock, W.; Doblhofer, K. Preparation and properties of insoluble films of cyclodextrin condensation polymers. $J$. Inclusion Phenom., 1992, 13, 257.

[93] Kutner, W. Volta-potential and electrochemical quartz crystal microbalance studies of the ion-exchange membrane properties of the $(\alpha$-cyclodextrin polymer film)/(4-nitrophenol/4-nitrophenolate) inclusion system. Electrochim. Acta, 1992, 37, 1109.

[94] D’Souza, F.; Hsieh, Y.Y.; Wickman, H.; Kutner, W. $\beta$-cyclodextrin and carboxymethylated $\beta$-cyclodextrin polymer film modified electrodes, hosting cobalt porphyrins, as sensors for electrocatalytic determination of oxygen dissolved in solution. Electroanalysis, 1997, 9, 1093.

[95] Kutner, W.; Wu, H.; Kadish, K.M. Condensation $\alpha$-cyclodextrin polymer membrane with covalently immobilized glucose oxidase and molecularly included mediator for amperometric glucose biosensor. Electroanalysis, 1994, 6, 934.

[96] Chen, Q.; Pamidi, P.V.A.; Wang, J.; Kutner, W. $\beta$-Cyclodextrin cation exchange polymer membrane for improved secondgeneration glucose biosensors. Anal. Chim. Acta, 1995, 306, 201.

[97] Harada, A.; Furue, A.; Nozakura, S.-I. Inclusion of aromatic compounds by a $\beta$-cyclodextrin-epichlorohydrin polymer. Polym. J., 1981, 13, 777.

[98] Cserhati, T.; Oros, G.; Fenyvesi, E.; Szejtli, J. Inclusion complexing by water-soluble $\beta$-cyclodextrin polymers. J. Inclusion Phenom., 1984, 1, 395.

[99] Szeman, J.; Fenyvesi, E.; Szejtli, J.; Ueda, H.; Machida, Y.; Nagai, T. Water soluble cyclodextrin polymers: Their interaction with drugs. J. Inclusion Phenom., 1987, 5, 427.

[100] Svancara, I.; Vytras, K.; Barek, J.; Zima, J. Carbon paste electrodes in modern electroanalysis. Crit. Rev. Anal. Chem., 2001, 31, 311.

[101] Kalchar, K. Chemically modified carbon paste electrodes in voltammetric analysis. Electroanalysis, 1990, 2, 419.

[102] Radi, A.E. Applications of stripping voltammetry at carbon paste and chemically modified carbon paste electrodes to pharmaceutical analysis. Curr. Pharm. Anal., 2006, 2, 1.

[103] He, P.; Ye, J.; Fang, Y.; Suzuki, I.; Osa, T. Voltammetric responsive sensors for organic compounds based on organized selfassembled lipoyl- $\beta$-cyclodextrin derivative monolayer on a gold electrode. Anal. Chim. Acta, 1997, 337, 217.

[104] Suzuki, I.; Egawa, Y.; Anzai, J.I. Electrochemical responses of catecholamines at a cyclodextrin monolayer-modified electrode. Bunseki Kagaku, 2002, 51, 403. 
[105] Fragoso, A.; Almirall, E.; Cao, R.; Echegoyen, L.; González-Jonte, R. A supramolecular approach to the selective detection of dopamine in the presence of ascorbate. Chem. Commun., 2004, 10, 2230.

[106] Li, J.; Wu, X.; Yu, Y.; Le, S. Self-assembled sulfonated $\beta$ Cyclodextrin layer on gold electrode for the selective electroanalysis of dopamine. J. Solid State Electrochem., 2009, 13, 1811.

[107] Mertins, O.; Buriez, O.; Labbé, E.; Fang, P.P.; Hillard, E.; Vessières, A.; Jaouen, G.; Tian, Z.Q.; Amatore, C. Further insights into hydrophobic interactions between ferrocenyl-tamoxifen drugs and non-polar molecular architectures at electrode surfaces. $J$. Electroanal. Chem., 2009, 635, 13 .

[108] Ferancová, A.; Korgová, E.; Buzinkaiová, T.; Kutner, W.; Štěpánek, I.; Labuda, J. Electrochemical sensors using screenprinted carbon electrode assemblies modified with the $\beta$ cyclodextrin or carboxymethylated $\beta$-cyclodextrin polymer films for determination of tricyclic antidepressive drugs. Anal. Chim. Acta, 2001, 447, 47.

[109] Ferancová, A.; Labuda, J.; Kutner, W. Electrochemical quartz crystal microbalance study of accumulating properties of the $\beta$ cyclodextrin and carboxymethylated $\beta$-cyclodextrin polymer films with respect to the azepine and phenothiazine type antidepressive drugs. Electroanalysis, 2001, 13, 1417.

[110] Shang, F.; Zhou, L.; Mahmoud, K.A.; Hrapovic, S.; Liu, Y.; Moynihan, H.A.; Glennon, J.D.; Luong, J.H.T. Selective nanomolar detection of dopamine using a boron-doped diamond electrode modified with an electropolymerized sulfobutylether- $\beta$ cyclodextrin-doped poly(N-acetyltyramine) and polypyrrole composite film. Anal. Chem., 2009, 81, 4089.

[111] Izaoumen, N.; Bouchta, D.; Zejli, H.; El Kaoutit, M.; Temsamani, K.R. The electrochemical behavior of neurotransmitters at a poly (pyrrole- $\beta$-cyclodextrin) modified glassy carbon electrode. Anal. Lett., 2005, 38, 1869.

[112] Majewska, U.E.; Chmurski, K.; Biesiada, K.; Olszyna, A.R.; Bilewicz, R. Dopamine oxidation at per(6-deoxy-6-thio)- $\alpha$ cyclodextrin monolayer modified gold electrodes. Electroanalysis, 2006, 18, 1463.

[113] Yang, Y.; Lei, C.X.; Liu, Z.M.; Liu, Y.L.; Shen, G.L.; Yu, R.Q. Highly selective dopamine determination by using carboxymethylated $\beta$-cyclodextrin polymer film modified electrode. Anal. Lett., 2004, 37, 2267.

[114] Bouchta, D.; Izaoumen, N.; Zejli, H.; El Kaoutit, M.; Temsamani, K. R. A novel electrochemical synthesis of poly-3methylthiophene- $\gamma$ - cyclodextrin film: Application for the analysis of chlorpromazine and some neurotransmitters. Biosens. Bioelectron., 2005, 20, 2228.

[115] Lomillo, M.A.A.; Renedo, O.D.; Martínez, M.J.A. Optimization of a cyclodextrin-based sensor for rifampicin monitoring. Electrochim. Acta, 2005, 50, 1807.

[116] Bouchta, D.; Izaoumen, N.; Zejli, H.; El Kaoutit, M.; Temsamani, K. R. Electroanalytical properties of a novel PPY/ $\gamma$ cyclodextrin coated electrode. Anal. Lett., 2005, 38, 1019.
[117] Luk, H.N.; Jheng, R.F.; Tsai, T.C.; Wu, R.J. Novel electrochemical impedance detection for rocuronium by using polypyrrole and cyclodextrin as the sensing material. Sens. Lett., 2009, 7, 1093.

[118] Frasconi, M.; Mazzei, F. Electrochemical and surface plasmon resonance characterization of $\beta$-cyclodextrin-based self-assembled monolayers and evaluation of their inclusion complexes with glucocorticoids. Nanotechnology, 2009, 20, 285502.

[119] Izaoumen, N.; Cubillana-Aguilera, L.M.; Naranjo-Rodríguez, I.; de Cisneros, J.L.H.; Bouchta, D.; Temsamani, K.R.; PalaciosSantander, J.M. $\beta$-Sonogel-Carbon electrodes: A new alternative for the electrochemical determination of catecholamines. Talanta, 2009, 78, 370 .

[120] Narasimha Rao, C.; Madhavi, G.; Venkateswarlu, P. Electrochemical behavior of anagrelide and its determination. Orient. J. Chem., 2009, 25, 425.

[121] Ferancová, A.; Korgová, E.; Mikó, R.; Labuda, J. Determination of tricyclic antidepressants using a carbon paste electrode modified with $\beta$-cyclodextrin. J. Electroanal. Chem., 2000, 492, 74.

[122] Wei, M.; Li, M.; Li, N.; Gu, Z.; Duan, X. Electrocatalytic oxidation of norepinephrine at a reduced $\mathrm{C}_{60}$-[dimethyl-( $\beta$-cyclodextrin $\left.)\right]_{2}$ and Nafion chemically modified electrode. Electrochim. Acta, 2002, 47, 2673.

[123] Yáñez, C.; Núñez-Vergara, L.J.; Squella, J. A. Determination of nitrendipine with $\beta$-cyclodextrin modified carbon paste electrode. Electroanalysis, 2002, 14, 559.

[124] Reddy, T.M.; Sreedhar, M.; Reddy, S.J. Electrochemical determination of sparfloxacin in pharmaceutical formulations and urine samples using a $\beta$-cyclodextrin modified carbon paste electrode. Anal. Lett., 2003, 36, 1365.

[125] Reddy, M.T.; Balaji, K.; Reddy, J.S. Voltammetric behavior of some fluorinated quinolone antibacterial agents and their differential pulse voltammetric determination in drug formulations and urine samples using a $\beta$-cyclodextrin-modified carbon-paste electrode. J. Anal. Chem., 2007, 62, 168.

[126] El-Hady, D.; El-Maali, N. Selective square wave voltammetric determination of $(+)$-catechin in commercial tea samples using beta-cyclodextrin modified carbon paste electrode. Microchim. Acta, 2008, 161, 225.

[127] Casas-Solvas, J.M.; Ortiz-Salmerón, E.; Fernández, I.; GarcíaFuentes, L.; Santoyo-González, F.; Vargas-Berenguel, A Ferrocene- $\beta$-cyclodextrin conjugates: Synthesis, supramolecular behavior, and use as electrochemical sensors. Chem. Eur. J., 2009, 15,8146 .

[128] Kataky, R.; Parker, D. Sensitive and specific electrochemical sensors for charge-diffuse cations: Use of lipophilic cyclodextrins and an enzyme relay for the determination of acetylcholine. Analyst, 1996, 121, 1829.

[129] Villalonga, R.; Fujii, A.; Shinohara, H.; Asano, Y.; Cao, R.; Tachibana, S.; Ortiz, P. Supramolecular-mediated immobilization of L-phenylalanine dehydrogenase on cyclodextrin-coated $\mathrm{Au}$ electrodes for biosensor applications. Biotechnol. Lett., 2007, 29, 447. 